\title{
Structural Reinforcement and Sealing Ability of Temporary Fillings in Premolar with Class II MOD Cavities
}

\author{
${ }^{1}$ Yuri Dal Bello, ${ }^{2}$ João Vicente Barbizam, ${ }^{3}$ Vinicius Rosa
}

\begin{abstract}
Aim: To evaluate the capability to reinforce tooth structure and sealing ability of temporary filling materials in premolars with MOD cavities. The hypothesis is that temporary filling materials can concomitantly prevent microleakage and increase fracture resistance.
\end{abstract}

Materials and methods: Premolars received root canal treatment and MOD cavities. Cavities were restored with noneugenol cement (CIM), glass ionomer cement (GIC) or light curable composite (BIO). Higid and without restoration were controls. Materials for flexual strength and teeth were tested for microleakage and compressive strength.

Results: GIC and Higid presented similar compressive strength, higher than other groups. Bio and GIC presented similar flexura strength higher than $\mathrm{BIO}$. CIM and $\mathrm{BIO}$ showed similar microleakage lower than GIC.

Conclusion: The hypothesis was rejected as filling materials tested failed to prevent microleakage and to increase fracture resistance concomitantly.

Clinical significance: GIC may be considered to restore weakened teeth subjected to occlusal loads. BIO and CIM are better choices to microleakage in teeth not subjected to mechanical stresses.

Keywords: Dental materials, Root canal treatment, Dental prosthesis, Fracture resistance, MOD cavity.

How to cite this article: Bello YD, Barbizam JV, Rosa V. Structural Reinforcement and Sealing Ability of Temporary Fillings in Premolar with Class II MOD Cavities. J Contemp Dent Pract 2014;15(1):66-70.

Source of support: Nil

Conflict of interest: None

\section{INTRODUCTION}

The amount of tooth structure lost during endodontic access may decrease the tooth resistance to fracture. The access

\footnotetext{
${ }^{1,3}$ Assistant Professor, ${ }^{2}$ Resident

${ }^{1}$ Department of Endodontics, University of Passo Fundo-Faculty of Dentistry, RS, Brazil

${ }^{2}$ Department of Endodontics, University of Washington, School of Dentistry, WA, United States

${ }^{3}$ Department of Oral Sciences, National University of Singapore Faculty of Dentistry, Singapore
}

Corresponding Author: Vinicius Rosa, Assistant Professor Department of Oral Sciences, National University of SingaporeFaculty of Dentistry, Singapore, Phone: 6567795555, e-mail: denvr@nus.edu.sg opening itself decreases the relative rigidity of the tooth by $5 \% .^{1}$ Teeth with four walls of remaining coronal dentin has significantly higher fracture resistance than teeth with only three walls. ${ }^{2}$ Regarding root strength, the thickness of the residual root structure is the major factor to maintain fracture resistance. ${ }^{3}$

Likewise, prosthetic preparation also removes sound tissue decreasing tooth fracture resistance. ${ }^{4}$ Regarding cavities configuration for direct and indirect inlay restorations, lower fracture strength was observed for indirect cavity preparations as compared to direct ones due to the removal of additional tooth structure. ${ }^{5}$ The loss of one marginal ridge decreases tooth rigidity by $46 \%$ while a mesio-occlusal distal (MOD) preparation, where both marginal ridges are removed, results in a dramatic loss of $63 \%$ relative cuspal rigidity. ${ }^{6}$

The sum of adverse effects of loosening sound mineralized structure due to root canal treatment and prosthetic preparation is a major concern regarding teeth fracture specially for posterior teeth, such as maxillary premolars that are more prone to cusp deflection and fracturing under high masticatory stresses. ${ }^{7}$ In fact, premolar fracture strength decreases up to $55 \%$ when teeth with MOD preparation undergo through root canal treatment. ${ }^{4}$ The association of endo dontic access and MOD preparation produces a dramatic increase in cuspal deflection even when low intensity loads are applied, resulting in teeth even more susceptible to fracture. ${ }^{8}$

If root canal treatment is not finalized in a single appointment, antimicrobial agents can be used for intracanal antisepsis to prevent the microorganisms to growth between appointments. During the interim appointments it is necessary the use of biocompatible temporary fillings. Ideally, these materials should reinforce the remaining structure to prevent fracture and to be dimensionally stable once expansion over time can lead to fracture of weakened cusps and shrinkage can allow bacterial percolation. ${ }^{9,10}$

The objective of this study is to verify the performance of temporary fillings in teeth with MOD preparation regarding fracture strength and ability to prevent microleakage. The hypothesis to be tested is that temporary filling materials are able prevent microleakage and to increase fracture resistance concomitantly. 


\section{MATERIALS AND METHODS}

Forty higid human maxillary premolars were endodontically accessed with a 1014 diamond high-speed bur with coolant spay. The coronal thirds of the teeth were flared by using Gates-Glidden drills \#3 and \#2. After visual working length determination, the root canals were enlarged up to a K-file \#35 under $10 \mathrm{ml}$ of $2.5 \%$ sodium hypochlorite $(\mathrm{NaOCl})$ irrigation. $3 \mathrm{ml}$ of $17 \%$ trisodic EDTA irrigation for 1 minute was used for smear layer removal followed by additional 3 $\mathrm{ml}$ of $2.5 \% \mathrm{NaOCl}$ as a final rinse. The root canals were filled by using the thermomechanical compaction of gutta-percha and zinc-oxide eugenol-based root canal sealer (EndoFill; Dentsply, Petropolis, Brazil).

After root canal treatment, MOD cavities were prepared using diamond burs \#1064, 1093, 2130 (Kg Sorensen, Cotia, Brazil), with the occlusal dimension equals to the half of the intercuspal dimension. Occlusal and proximal depths of the cavities were 2 and $4 \mathrm{~mm}$, respectively. Teeth were randomly divided in groups $(\mathrm{n}=10)$ and assigned to be restored. Materials characteristics and restorative procedures are briefly presented in Table 1 . Controls were higid tooth (no root treatment nor MOD preparation) and teeth with endodontic treatment and MOD preparation without restoration (Cavity). Teeth were stored for 40 days $\left(37^{\circ} \mathrm{C}\right.$ and $100 \%$ humidity) and embedded in curing acrylic resin to be tested under compression static loading (steel ball, Ø 3.0 $\mathrm{mm}$ ) with a crosshead speed of $0.5 \mathrm{~mm} / \mathrm{min}$ until fracture. When catastrophic failure was not observed, the test was stopped when fragments or cracks in the root measuring 3 $\mathrm{mm}$ were observed. To test the flexural strength of filling materials, 10 beam-shaped specimens $(20 \mathrm{~mm}$ in lenght $\times 4$ $\mathrm{mm}$ height $\times 1 \mathrm{~mm}$ thickness) were fabricated and allowed to set for 1 day $\left(37^{\circ} \mathrm{C}\right.$ and $95 \%$ relative humidity). After, bars were positioned over support rollers ( $5 \mathrm{~mm}$ in diameter, 16 $\mathrm{mm}$ centre-to-centre distance between support rollers). The load was applied across a $4 \mathrm{~mm}$ wide face with a crosshead speed of $0.5 \mathrm{~mm} / \mathrm{min}$ until fracture. Flexural strength was calculated according to equation 1 , where $\mathrm{P}$ is the fracture load $(\mathrm{N})$; 1 is the test span (center-to-center distance, $\mathrm{mm}$ ); $\mathrm{W}$ is the width of the specimen ( $\mathrm{mm}$ ) and $\mathrm{b}$ is the thickness of the specimen (mm). ${ }^{11}$

$$
\sigma=\frac{3 \mathrm{PI}}{2 \mathrm{wb}^{2}} \text { Eq. } 1
$$

According to the normality test (Kolmogorov-Smirnov, $\mathrm{p}>0.05)$, the strength data were normally distributed. Therefore, the fracture load and flexural strength results were analyzed statistically by means of one-way ANOVA and Tukey's test $(\alpha=0.05)$.

For microleakage test, three cavities were prepared in 6 non-carious freshly extracted third molar crowns using diamond burs \#3145 and FG58L (KG Sorensen, São Paulo, Brazil). The box type cavities were prepared in vestibular and both proximal surfaces measuring $4 \mathrm{~mm}$ width and $3 \mathrm{~mm}$ depth. The gingival floor was prepared $3 \mathrm{~mm}$ above the cementoenamel junction. Teeth were restored in a manner that every material was used three times in each surface then were stored for 1 day $\left(37^{\circ} \mathrm{C}\right.$ and $95 \%$ relative humidity). Teeth were coated with nail varnish, except for a window area that included the restoration and $1 \mathrm{~mm}$ around it, and soaked in $1 \%$ methylene blue dye solution at $24^{\circ} \mathrm{C}$ for 24 hours, then rinsed under running water for 1 hour. Teeth were longitudinally sliced using a diamond wheel saw $(250 \mathrm{rpm}$, water refrigeration). After, the two central $1 \mathrm{~mm}$ thick slices (4 surfaces) were examined under an optical microscope (Meiji EMZ-TR, Meiji Techno Co. Ltd., Tokyo, Japan). The degree of dye penetration was registered according to the following scores: $0=$ no dye penetration; $1=$ dye penetration into the enamel part of the cavity wall; $2=$ dye penetration into the dentin part of the cavity wall but not including the pulpal floor of the cavity; 3 = dye penetration including the pulpal floor of the cavity. ${ }^{12}$

Results were statistically analyzed using Kruskal Wallis at a significant level of $5 \%(\alpha=0.05)$.

Spearman's rank test $(\alpha=0.05)$ was used to assess the existence of correlation between material's sealing abbility (microleakage) and its capability to increase root structure strength (fracture load).

\section{RESULTS}

Table 2 shows the fracture load obtained for groups tested and the flexural strength of three materials obtained with three-point bending flexural test. Higid presented the higher fracture load as compared and similar to GIC. For the flexural strength, CIM presented the lower strength value as compared to GIC and BIO that were statistically similar.

The dye penetration frequencies, dye penetration score means, ranking and statistical grouping from microleakage test are summarized in Table 3. GIC presented the higher microleakage score as compared to GIC and BIO that were statistically similar. Figure 1 shows microleakage patterns commonly observed for the materials tested.

There was a moderate correlation (Spearman rank cor- relation efficient: 0.5 ) between fracture load and microleakage for the materials tested.

\section{DISCUSSION}

Although higid teeth rarely fracture from the normal stresses of mastication once the occlusal load received is harmonically transmitted throughout its structure and surrounding tissues, fracture can happens in teeth that have undergone 
Table 1: Materials used

\begin{tabular}{lll}
\hline Materials & Composition & Procedure \\
\hline Bioplic $(\mathrm{BIO})^{\dagger}$ & $\begin{array}{l}\text { Silicium dioxide, dimethacrylates, } \\
\text { inorganic filler }\end{array}$ & $\begin{array}{l}\text { Inserted in cavity using plastic spatule without previous } \\
\text { hybridization followed by } 60 \text { seconds photopolimerization } \\
\text { with } 1000 \mathrm{~W} \text { Led curing unit }\end{array}$ \\
Cimpat N $(\mathrm{CIM})^{\ddagger}$ & $\begin{array}{l}\text { A premixed noneugenol temporary } \\
\text { filling material }\end{array}$ & $\begin{array}{l}\text { Material inserted with a plastic spatule and allowed to set } \\
\text { in contact with a moist gauze }\end{array}$ \\
Vidrion $\mathrm{R}(\mathrm{GIC})^{\S}$ & $\begin{array}{l}\text { Glass ionomer cement. } \\
\text { Powder: aluminum silicate glass. } \\
\text { Liquid: copolymers of polyacrylic, } \\
\text { tartaric and itaconic acids }\end{array}$ & $\begin{array}{l}1: 1 \mathrm{P} / \mathrm{L} \text { ratio was manipulated for } 45 \text { seconds inserted in } \\
\text { cavity using Centrix syringe. Cement was allowed to set } \\
\text { for 48 hours. }\end{array}$ \\
\hline
\end{tabular}

${ }^{\pi}$ According to manufacturer information, ${ }^{\dagger}$ Biodinâmica Ltda, Ibiporã, Brazil, ${ }^{\ddagger}$ Cimpat N, Septodont, Saint Maur des Fosses. France, §S White, Petropolis, Brazil

Table 2: Mean \pm standard deviation for fracture load and flexural strength (data were evaluated seperatedely for each test

\begin{tabular}{lll}
\hline Groups & Fracture load $(N)$ & Flexural strenght $(\mathrm{MPa})$ \\
\hline Higid & $10006.0 \pm 273.7^{\mathrm{a}}$ & - \\
GIC & $790.3 \pm 259.8^{\mathrm{ab}}$ & $29.2 \pm 4.3^{\mathrm{e}}$ \\
CIM & $622.1 \pm 157.2^{\mathrm{bc}}$ & $5.9 \pm 2.0^{\mathrm{f}}$ \\
BIO & $330.4 \pm 105.6^{\mathrm{cd}}$ & $28.7 \pm 7.3^{\mathrm{e}}$ \\
Cavity & $324.9 \pm 155.2^{\mathrm{d}}$ & - \\
\hline
\end{tabular}

Group means followed by the same letter are not statistically different at $p=0.05$ )

cavity preparation. It has been recognized that resistance to restoration failure is not solely a biological concern, but that the cavity shape, dimensions and the state of stress have to be considered. The decrease of $\sim 70 \%$ in the fracture load observed for Cavity as compared to Higid may be explained by the structure lost and geometry modification that changes substrates volumes leading to different stress distribution within the dental structure and loss of resistance.Our results are fairly higher than other reported, where the fracture strength for unrestored premolar with MOD preparation was $50 \%$ lower as compared to the higid ones. ${ }^{13}$ Maintaining tooth structures intact as much as possible is the best choice to avoid structure weakening. ${ }^{14}$

In premolar with MOD preparations and endodontic access, the cusps are virtually isolated, due to the removal of tissue between the access opening and proximal boxes resulting in pronounced cuspal deflection..$^{15}$ The use of GIC to restore the large-sized cavity was able to improve the fracture resistance of the tooth to a level statistically similar to the observed in Higid teeth.

It has been shown that under compressive load testing, maxillary premolars with MOD cavities restored with microhybrid and nanofilled composites presented lower cuspal fracture resistance then unprepared ones. ${ }^{16}$ As compared to resin composites, GIC presents modest values of the flexural strength. ${ }^{17}$ Although GIC and BIO present similar values of flexural strength (Table 2), the first is capable to self-adhere to dental tissue and this is what renders to the GIC the capability to reinforce the damaged tooth structure not observed for BIO in spite of to present the same flexural strength (see Table 2). ${ }^{18}$ It has been shown that unbonded restorations, such as amalgam, are mechanically passive while bonded ones are able to splint the cusps minimizing cuspal flexure in MOD cavities. This culminates in increase of the stiffness diminishing the risk of partial fracture and subsequently fatigue fracture. ${ }^{19}$ Based in this concept, considering teeth with extensive prosthetic preparations such as MOD, it is feasible to suggest that for the same level of flexural strength, temporary filling materials that bond to the tooth structure have the potential to increase the fracture resistance upon compressive stress as observed in Table 2.

Temporary filings must be able to protect the canal system from exterior moisture and prevent bacterial invasion. Here we assessed the sealing ability of the three materials and although GIC showed the best performance considering the potential to increase tooth fracture resistance, it failed to avoid dye penetration and leakage occurred beyond the dentin-enamel junction in four out of six samples (Table 3). The limited ability of GIC to prevent interfacial leakage has been previously reported and may be due to the material's sensitivity to moisture during placement and early set and the dehydration after setting that results in crazing and cracking. ${ }^{12,20,21}$

At least half of all samples for BIO and CIM (see Table 3) successfully prevented any leakage along the tooth/filling material interface. The dye penetration observed in $50 \%$ of $\mathrm{BIO}$ and $33 \%$ of $\mathrm{BIO}$ and CIM samples, were restricted to the enamel portion of the cavity wall. BIO is a light-curable dimethacrylate-based material. Its high translucency allows the light to go through out the material and to achieve a degree of conversion adequate to prevent leakage even without being bonded. A previous study also reported superior sealing ability of light-curable resin composite to prevent microleakage, however the material used required etching and use of a bonding agent before placement. ${ }^{22} \mathrm{BIO}$ 
Table 3: Microleakage scores and statistics from the three materials tested

\begin{tabular}{lllllll}
\hline Groups & 0 & 1 & 2 & 3 & Score mean & Mean rank \\
\hline GIC & 0 & 2 & 1 & 3 & 2.1 & $14.7^{\mathrm{a}}$ \\
BIO & 3 & 3 & 0 & 0 & 0.5 & $7.5^{\mathrm{b}}$ \\
CIM & 4 & 2 & 0 & 0 & 0.3 & $6.3^{\mathrm{b}}$ \\
\hline
\end{tabular}

Mean values followed by the same letter are not statistically different at $p=0.05$
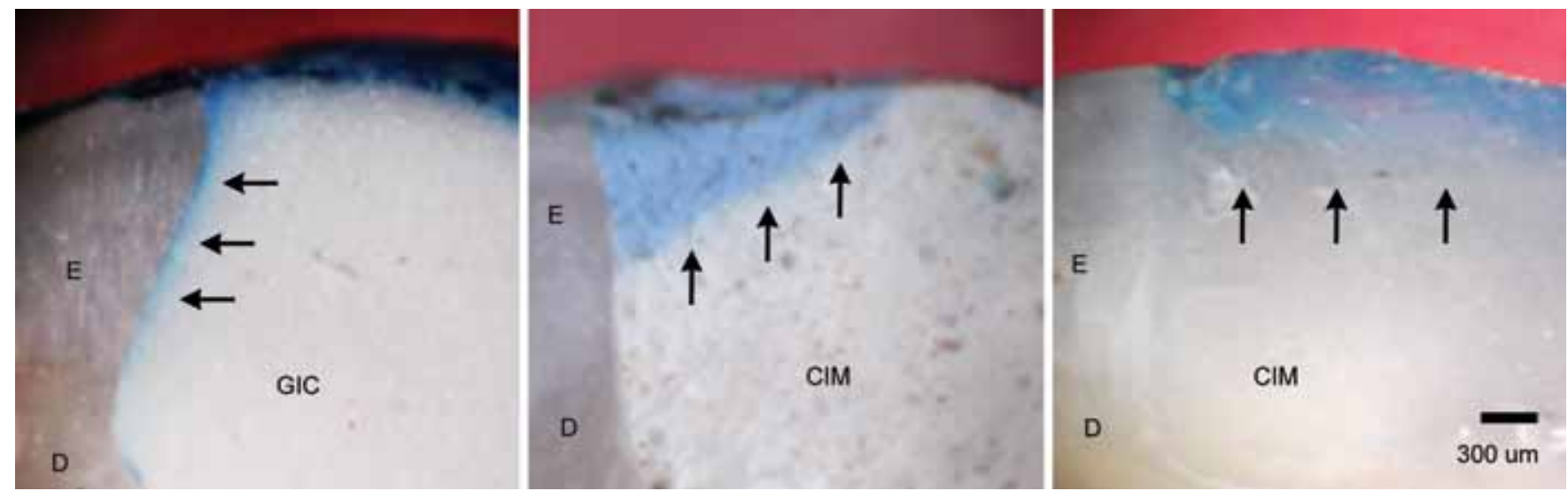

Fig. 1: Microleakage patterns observed for the materials tested (arrows indicate dye penetration)

claims to be likely to enlarge in humid environment and this could enhance its adaptation to the cavity, however, it has been shown that the water uptake of BIO is not so pronounceable. ${ }^{20}$ The high energy density delivered to the material during its polymerization allied to its translucency were possibly able to result in a material cured enough that could prevent dye penetration into the interface as it can be observed in Figure 1. The high level of water intake presented by CIM results in hygroscopic expansion that seals the tooth/filling interface. ${ }^{14}$ One may see in Figure 1 that the bulk of CIM material is highly colored and there is no dyeing in the tooth/material interface. This renders to this material the capability to provide a temporary leak-proof seal.

The lack of strong positive correlation between material's sealing ability and capability to reinforce the remaining structure must be considered when choosing the temporary filling material. Should be emphasized that although CIM presented less microleakage as compared to GIC, the first does no support the application of small but repetitive forces that can lead to a fatigue failure of the material resulting in percolation of bacteria into the root canal. ${ }^{23}$ Thus, from the mechanical perspective, this class of filling material should be preferably used in areas that are not subjected to direct occlusal loads from antagonist and GIC would be a better choice to restored MOD cavities in teeth subjected to masticatory stress.

\section{CONCLUSION}

The hypothesis of this study was rejected since the materials tested were not able to prevent microleakage and to increase fracture resistance of premolars with MOD preparation concomitantly. BIO and CIM presented the lower microleakage scores and can be considered good choices to seal cavities in order to prevent bacterial percolation in the interface tooth/material, however GIC presented the higher fracture resistance and this should be considered when selecting a temporary material to restore highly weakened teeth subjected to direct occlusal loads.

\section{REFERENCES}

1. Reeh ES, Messer HH, Douglas WH. Reduction in tooth stiffness as a result of endodontic and restorative procedures. J Endod 1989; 15(11):512-516.

2. Arunpraditkul S, Saengsanon S, Pakviwat W. Fracture resistance of endodontically treated teeth: three walls versus four walls of remaining coronal tooth structure. J Prosthodont 2009;18(1): 49-53.

3. Zogheib LV, Saavedra Gde S, Cardoso PE, Valera MC, Araujo MA. Resistance to compression of weakened roots subjected to different root reconstruction protocols. J Appl Oral Sci 2011; 19(6):648-654.

4 Howe CA, McKendry DJ. Effect of endodontic access preparation on resistance to crown-root fracture. J Am Dent Assoc 1990;121(6):712-715.

5. Mondelli J, Sene F, Ramos RP, Benetti AR. Tooth structure and fracture strength of cavities. Braz Dent J 2007;18(2):134-138.

6 Plotino G, Buono L, Grande NM, Lamorgese V, Somma F. Fracture resistance of endodontically treated molars restored with extensive composite resin restorations. J Prosthet Dent 2008; 99(3):225-232.

7. Larson TD, Douglas WH, Geistfeld RE. Effect of prepared cavities on the strength of teeth. Oper Dent 1981;6(1):2-5.

8. Gonzalez-Lopez S, De Haro-Gasquet F, Vilchez-Diaz MA, Ceballos L, Bravo M. Effect of restorative procedures and 
occlusal loading on cuspal deflection. Oper Dent 2006;31(1): 33-38.

9. Laustsen MH, Munksgaard EC, Reit C, Bjorndal L. A temporary filling material may cause cusp deflection, infractions and fractures in endodontically treated teeth. Int Endod J 2005; 38(9):653-657.

10. Ciftci A, Vardarli DA, Sonmez IS. Coronal microleakage of four endodontic temporary restorative materials: an in vitro study. Oral Surg Oral Med Oral Pathol Oral Radiol Endod 2009; 108(4):e67-70.

11. ISO. ISO 6872:2008 Dentistry_Ceramic Materials. 1999.

12. Bona AD, Pinzetta C, Rosa V. Effect of acid etching of glass ionomer cement surface on the microleakage of sandwich restorations. J Appl Oral Sci 2007;15(3):230-234.

13. Siso SH, Hurmuzlu F, Turgut M, Altundasar E, Serper A, Er K. Fracture resistance of the buccal cusps of root filled maxillary premolar teeth restored with various techniques. Int Endod J 2007;40(3):161-168.

14. Lin $\mathrm{CL}$, Chang $\mathrm{CH}$, Wang $\mathrm{CH}$, Ko $\mathrm{CC}$, Lee HE. Numerical investigation of the factors affecting interfacial stresses in an MOD restored tooth by auto-meshed finite element method. J Oral Rehabil 2001;28(6):517-525.

15. Panitvisai $\mathrm{P}$, Messer HH. Cuspal deflection in molars in relation to endodontic and restorative procedures. J Endod 1995; 21(2):57-61.

16. Taha DG, Abdel-Samad AA, Mahmoud SH. Fracture resistance of maxillary premolars with class II MOD cavities restored with
Ormocer, Nanofilled and Nanoceramic composite restorative systems. Quintessence Int 2011;42(7):579-587.

17. Bapna MS, Gadia CM, Drummond JL. Effects of aging and cyclic loading on the mechanical properties of glass ionomer cements. Eur J Oral Sci 2002;110(4):330-334.

18. De Munck J, Van Landuyt K, Peumans M, Poitevin A, Lambrechts P, Braem M, et al. A critical review of the durability of adhesion to tooth tissue: methods and results. J Dent Res 2005; 84(2):118-132.

19. Zidan O, Abdel-Keriem U. The effect of amalgam bonding on the stiffness of teeth weakened by cavity preparation. Dent Mater 2003;19(7):680-685.

20. Pieper CM, Zanchi CH, Rodrigues-Junior SA, Moraes RR, Pontes LS, Bueno M. Sealing ability, water sorption, solubility and toothbrushing abrasion resistance of temporary filling materials. Int Endod J 2009;42(10):893-899.

21. McLean JW, Powis DR, Prosser HJ, Wilson AD. The use of glass-ionomer cements in bonding composite resins to dentine. Br Dent J 1985;158(11):410-414.

22. Jenkins S, Kulild J, Williams K, Lyons W, Lee C. Sealing ability of three materials in the orifice of root canal systems obturated with gutta-percha. J Endod 2006;32(3):225-227.

23. Liberman R, Ben-Amar A, Frayberg E, Abramovitz I, Metzger Z. Effect of repeated vertical loads on microleakage of IRM and calcium sulfate-based temporary fillings. J Endod 2001; 27(12):724-729. 